\title{
Aplicabilidade do direito de arrependimento no comércio eletrônico em relação aos produtos personalizados
}

\author{
Applicability of the right to repentance at the \\ e-commerce in respect the customized products
}

Fabrício Germano Alves Universidade Federal do Rio Grande do Norte, Natal/RN - Brasil

Halissa Reis Universidade Federal do Rio Grande do Norte, Natal/RN - Brasil

Resumo O direito de arrependimento presente no art. 49 do Código de Defesa do Consumidor possibilita-o adquirir um bem fora do estabelecimento comercial e em até sete dias após recebimento arrepender-se do contrato realizado e extingui-lo. Porém, novas práticas comerciais surgiram, como o comércio eletrônico, havendo necessidade de atualização do CDC, iniciada pelo PLS n ${ }^{\circ}$ 281/2012, porém ainda em tramitação pelas casas do Congresso Nacional, seguida do Decreto Presidencial $\mathrm{n}^{\circ} 7.962 / 2013$, que regulou o comércio eletrônico. O PLS $\mathrm{n}^{\circ}$ 281/2012 trouxe a discussão da limitação ao direito de arrependimento para produtos personalizados, defendida por parte da doutrina e ainda não incorporada pela jurisprudência. Por meio de uma pesquisa dedutiva e hipotética com abordagem qualitativa e descritiva o presente texto analisa a aplicação desse direito direcionado aos produtos personalizados, identificando os sujeitos da relação e algumas situações específicas. Assim, apesar do arrependimento do consumo produtos personalizados poder gerar ônus ao fornecedor, e iminente abuso de direito e 
a boa-fé, não deve o consumidor ser penalizado com a diminuição de um direito, uma vez que não the foi oportunizado, como em qualquer compra fora do estabelecimento comercial realizar juízo de valor mais elaborado, cabendo ao fornecedor arcar com tal ônus, já que esta situação é inerente a forma de comércio que optou por realizar. Ademais o Código Civil e o Código de Defesa do Consumidor rechaçam o abuso do direito e o desrespeito a boa-fé, prevendo inclusive sanções para tais casos, estando o fornecedor nesse contexto respaldado caso os identifique, sendo apenas negativa tal limitação.

Palavras-chave: Direito De ARREPENDIMENTO; Produto PERsonalizado; COMÉRCIO ELETRÔNICO.

Abstract The right of repentance in art. 49 of the Code of Consumer Protection makes it possible for him to acquire a product outside the commercial establishment and within seven days after receipt regret of the contract and extinguish it. However, new commercial practices have emerged, such as e-commerce, and there is a need to update the CDC initiated by PLS n ${ }^{\circ} 281 / 2012$, but still in progress at the National Congress houses, followed by Presidential Decree 7.962/2013 that regulated e-commerce. The PLS 281/2012 brought the discussion of the limitation to the right of repentance for personalized products, defended by the doctrine and not yet incorporated by the jurisprudence. Through a deductive and hypothetical research with descriptive and qualitative approach this paper seek to analyze the application of this right in relation to personalized products, identifying the subjects of the relationship, and some specific situations. Thus, although the repentance of a personalized products may generate a burden on the supplier, and imminent abuse of law and good faith, the consumer should not be penalized by the reduction of a right, since it was not given to him as in any purchase outside the establishment an accurate judgment, being incumbent on the supplier to bear such burden, since this is inherent in the form of trade he has chosen to carry out. In addition, the Civil Code and the Consumer's Defense Code reject the abuse of the right and disrespect good faith, 
providing sanctions for such behaviors, being the supplier in that context supported if identifies them, being only negative such limitation. Keywords: Right of RePentance; Custom Product; E-commerce.

\section{INTRODUÇão}

O Código de Defesa do Consumidor (CDC), instituído pela Lei Federal $n^{\circ} 8.078 / 90$, preconiza em seu artigo 49 que o consumidor pode desistir do contrato pactuado quando este for firmado fora do estabelecimento comercial, isto é, quando as partes não estão presentes fisicamente no mesmo local. Isso ocorre na perspectiva de proteger o consumidor das práticas comerciais abusivas capazes de influencia-lo a realizar uma compra por mero impulso, como também de divergências quanto à qualidade do produto, já que não lhe foi oportunizado tal análise anterior ao contrato firmado.

O consumidor possui o prazo decadencial de sete dias para refletir acerca de sua aquisição, verificando sua real necessidade ou até constatando a paridade das características informadas pelo fornecedor com as do produto entregue em sua casa. Logo, o direito de arrependimento ao permitir esse prazo de reflexão resguarda o consumidor de qualquer influência, interna ou externa, que tenha sofrido e que, passado o recebimento do produto ou serviço, faça com que não tenha mais pretensão em permanecer com o mesmo.

O Decreto Federal no 7962/2013, por sua vez, o regulamenta ao dispor sobre a contratação nesse tipo de comércio, inclusive trazendo disposições acerca do direito de arrependimento, tornando clara a forma que ele deve ser exercido, bem como os deveres do fornecedor quando diante da ciência da desistência.

Porém, o assunto ainda prescinde de mais atualizações. Ciente dessa necessidade, a Comissão Especial do Senado Federal para atualização do Código de Defesa do Consumidor, sob o Projeto de Lei do Senado $n^{\circ} 281 / 2012$, busca trazer para o art. 49 a inclusão de nove parágrafos dentre os quais prevê limitações em relação ao direito de arrependimento do consumidor. 
Quando da discussão a respeito da limitação, o Senador Federal Antonio Carlos Rodrigues, por meio da Emenda $n^{\circ} 26$ buscou elencar diversas possibilidades de mitigação ao direito de arrependimento, e um dos pontos refere-se aos produtos realizados sob encomenda pelo consumidor, ou seja, produtos personalizados.

Apesar de a Emenda mencionada ter sido aprovada parcialmente pela Comissão, quando somente em relação à aquisição de bilhetes aéreos, conforme o texto final do PLS n ${ }^{\circ} 281 / 2012$, foi permitido tratamento diferenciado de outros objetos contratuais, a discussão acerca da aplicação do direito do consumidor que adquire fora do estabelecimento comercial produtos personalizados e decide arrepender-se permanece na doutrina. Assim, surgem indagações quanto à possibilidade de utilização do direito de arrependimento na compra de produtos personalizados, bem como se há exceções ao exercício desse direito em geral.

Sendo assim, busca o presente trabalho, por meio de uma pesquisa dedutiva e hipotética com abordagem qualitativa e descritiva, analisar a aplicação do direito de arrependimento no que tange aos produtos personalizados, identificando os sujeitos da relação, as disposições contratuais entre as partes, bem como analisar algumas situações específicas relacionadas ao tema.

O presente texto tratará também dos elementos que configuram a relação de consumo, isto é, fornecedor e consumidor (subjetivos), produto e serviço (objetivos) e a identificação do destinatário final (causal ou finalístico), perfazendo a regulamentação do direito de arrependimento, sua natureza jurídica, e suas principais nuances no ordenamento jurídico.

Além disso, tratar-se-á igualmente do Projeto de Lei do Senado $n^{\circ}$ 281/2012, do Decreto Presidencial no 7962/2013, e da jurisprudência relativa ao direito de arrependimento nos casos de aquisição de produtos personalizados, no intuito de propor uma avaliação formativa em resposta às atuais discussões e entendimentos a respeito do tema proposto. 


\section{CONFIGURAÇÃo dA RELAÇÃo de CONSUMO NO COMÉRCIO ELETRÔNICO}

A Lei Federal $n^{\circ}$ 8.078, que instituiu o Código de Defesa do Consumidor (CDC) objetiva reduzir, no âmbito abstrato, as desigualdades entre consumidor e fornecedor ao disciplinar as relações jurídicas consumeristas. Contudo, para identificar o seu campo de incidência é preciso conhecer os elementos que compõem esse tipo de relação jurídica.

\subsection{Definição de consumidor}

$\mathrm{O}$ CDC possui quatro menções às definições de consumidor, em que "todas levam em consideração a caracterização do consumidor como destinatário final e a sua vulnerabilidade como fatores determinantes para a classificação de uma relação jurídica como relação de consumo" ${ }^{1}$.

Assim, a primeira delas está no caput do artigo $2^{\circ}$ do CDC, que se dispõe a definir o consumidor como: "toda pessoa física ou jurídica que adquire ou utiliza produto ou serviço como destinatário final". O atributo de destinatário final é decisivo para tal caracterização, sendo a partir daí irrelevante se tratar de pessoa física ou jurídica, podendo inclusive esta última ser considerada vulnerável na relação e obter proteção do referido Código.

Ademais, o parágrafo primeiro do mesmo artigo mencionado apresenta a segunda definição. Esta é no sentido de que a coletividade de pessoas, ainda que indeterminada, que intervenha em uma relação de consumo, deve ser considerada consumidora por equiparação. Esta coletividade deve ser atingida de alguma forma pela relação de consumo, porém não é imprescindível a ocorrência de danos. Nesse liame, o dispositivo em comento posssibilita que um conjunto de pessoas, mesmo que não seja pessoa jurídica (v.g., a massa falida), possa figurar como consumidora na relação ao adquirir um produto, tal qual o condomínio que contrata um serviço².

1 MATTOS, Analice Castor. Aspectos Relevantes dos Contratos de Consumo Eletrônico. Curitiba: Juruá, 2009, p. 46.

2 NUNES, Luiz Antonio Rizzato. Curso de Direito do Consumidor. 7. ed. São Paulo: Saraiva, 2012. p. 133. 
No entanto, o Código de Defesa do Consumidor não esclarece como deverá ser compreendida essa interferência em termos legais, restando apenas aos intérpretes do Direito o ônus de desempenhar tal papel $^{3}$. O parágrafo único do art. $2^{\circ}$ do CDC pode ser aplicado para uma tutela preventiva, na perspectiva de configurar a relação de consumo e permitir a utilização dos mecanismos de defesa coletiva do consumidor a fim de evitar danos ${ }^{4}$.

A terceira definição de consumidor está no artigo 17 do $\mathrm{CDC}^{5}$. Este dispositivo permite considerar consumidores por equiparação todos aqueles que tenham sido vítimas de evento advindo de uma relação de consumo, sendo desnecessária a sua participação no contrato que originou, contudo é imprescindível que tenham sido atingidos por um evento oriundo de tal relação.

Esses sujeitos são chamados de bystanders ${ }^{6}$. O fator determinante para sua participação na relação de consumo é a ocorrência de algum defeito no produto ou serviço capaz de causar um dano. Assim, os atingidos por tal dano se tornam partícipes na relação de consumo por equiparação. Sendo assim, torna-se possível afirmar que o artigo 17 do CDC trata da responsabilidade objetiva do fornecedor por fato do produto ou serviço, presente também no artigo 12 do mesmo Diploma legal, nos casos de acidente de consumo, trazendo segurança jurídica a todos os envolvidos no evento.

A quarta definição, por sua vez, está evidenciada no art. $29^{7}$ do CDC. Segundo este, são também equiparadas a figura do consumidor todas as pessoas, determinadas ou indeterminadas, que sejam expostas às práticas comerciais pré-contratuais, contratuais e pós-contratuais.

\footnotetext{
3 ALVES, Fabrício Germano. Proteção Constitucional do consumidor no âmbito da regulação publicitária. Natal: Espaço Internacional do Livro, 2013. p. 51.

$4 \quad$ Ibid., p. 52.

5 Art. 17. Para os efeitos desta Seção, equiparam-se aos consumidores todas as vítimas do evento.

6 ALVES, Fabrício Germano. Proteção Constitucional do consumidor no âmbito da regulação publicitária. Natal: Espaço Internacional do Livro, 2013. p. 52.

7 Art. 29. Para os fins deste Capítulo e do seguinte, equiparam-se aos consumidores todas as pessoas determináveis ou não, expostas às práticas nele previstas.
} 
Dessa forma, é possível compreender que aqueles que estiverem expostos a qualquer prática comercial (v.g., um anúncio publicitário) são equiparados e devem ser tratados como consumidores, estando consequentemente albergados pelo Código de Defesa do Consumidor. $\mathrm{Na}$ realidade nem sequer precisa existir consumo direto, basta que seja um consumidor em potencial ${ }^{8}$, para, por força do artigo 29 do CDC, ser compreendido e protegido como tal. Nesse caso o dano é presumido, independentemente de haver ou não prova de algum prejuízo?

O legislador, por meio dos artigos retro mencionados, traz um conceito abrangente para a figura do consumidor (elemento subjetivo da relação jurídica de consumo), sendo a pessoa física ou jurídica, uma coletividade de pessoas, aquelas atingidas por evento danoso decorrente da relação de consumo ou simplesmente expostas à uma prática comercial de consumo.

Contudo, resta esclarecer ainda que não podem ser compreendidos como consumidores aqueles que atuam como intermediários, realizando revenda ou repasse de produtos e/ou serviços. Isto quer dizer que a relação de consumo finda no consumidor, não abrangendo aquele adquire ou utiliza um produto ou serviço com intuito de revendê-lo, seja após montagem ou beneficiamento ${ }^{10}$.

\subsection{Conceito de fornecedor}

O fornecedor, outro elemento subjetivo da relação de consumo, é caracterizado conforme disciplina o caput do artigo terceiro do CDC, que atribui tal qualidade a toda pessoa, física ou jurídica, pública ou privada, nacional ou estrangeira, incluindo os entes despersonalizados, que atue em atividade de produção, montagem, criação, construção, transformação, importação, exportação, distribuição ou comercialização de produtos ou prestação de serviços.

8 NUNES, Luiz Antonio Rizzato. Curso de Direito do Consumidor. 7. ed. São Paulo: Saraiva, 2012. p. 134.

9 ALVES, Fabrício Germano. Proteção Constitucional do consumidor no âmbito da regulação publicitária. Natal: Espaço Internacional do Livro, 2013. p. 54.

10 ALMEIDA, João Batista de. Manual de Direito do Consumidor. São Paulo: Saraiva, 2003. p. 38 . 
Compreende-se que o fornecedor é qualquer pessoa, a título singular, que por meio do desempenho de atividade, mercantil ou civil, de maneira habitual, disponha no mercado produtos ou serviços, ou pessoa jurídica, com as mesmas atribuições, mantendo a forma habitual de atividade ${ }^{11}$.

No entanto, é importante frisar a habitualidade se torna característica imprescindível para a caracterização da figura do fornecedor e a consequente proteção pelo Código de Defesa do Consumidor, do contrário a relação será regida pelo Código Civil ${ }^{12}$.

Salienta-se também que o legislador trata a respeito da nacionalidade, permitindo que o fornecedor seja brasileiro ou estrangeiro, o que proporciona uma maior proteção ao consumidor no contexto do comércio globalizado, praticado geralmente em baixa escala pelas pessoas físicas, e em alta escala por pessoas jurídicas.

Há entendimento no Superior Tribunal de Justiça ${ }^{13}$ no sentido de que a identificação de um fornecedor é depreendida a partir do preenchimento das características do art. $3^{\circ}$ do CDC. De tal forma, tem-se um critério objetivo aplicado para a identificação de um elemento subjetivo, sendo a observância ou não quanto à natureza jurídica, o tipo de serviço prestado ou a finalidade lucrativa por vezes irrelevante, possibilitando que uma entidade beneficente seja considerada fornecedora, desde que preencha o disposto no já citado Diploma legal.

É importante frisar ainda que também podem ser considerados fornecedores as pessoas de Direito Público. Pela inteligência do artigo 22 do Código de Defesa do Consumidor, os serviços públicos devem ser obrigatoriamente fornecidos de forma adequada, eficiente, segura e, para os essenciais, de forma contínua. Diante do descumprimento do artigo em comento, o seu parágrafo único determina inclusive que

11 GRINOVER, Ada Pellegrini; et al. Código brasileiro de defesa do consumidor: comentado pelos autores do anteprojeto. 8. ed. Rio de Janeiro: Forense Universitária, 2004, p. 43.

12 TARTUCE, Flávio. Manual de Direito do Consumidor. 3. ed. São Paulo: Método. 2014. p. 67.

13 STJ. REsp. 519.310/SP. Terceira Turma. Rel. Min. Nancy Andrighi - Dj. 20.04.2004. 
as pessoas jurídicas de Direito Público poderão ser compelidas tanto a cumprir as obrigações contidas no caput quanto a reparar os danos advindos de seu descumprimento.

Reitere-se que o supracitado artigo abrange todo e qualquer serviço público, seja ele prestado diretamente pelo Estado ou por empresas privadas ${ }^{14}$. Há uma discussão sobre a possibilidade de interrupção dos serviços essenciais vedada pelo Código de Defesa do Consumidor, porém a jurisprudência demonstra que diante da não contraprestação reiterada de um serviço (inadimplência), mesmo que essencial, após aviso prévio torna-se possível a paralisação da prestação do mesmo sem que isso configure interrupção.

Tribunal de Justiça de São Paulo ${ }^{15}$ já se manifestou no sentido de que a continuidade dos serviços públicos prescinde de contraprestação, que deve ser adimplida pelo consumidor, sendo neste caso especificamente referente ao fornecimento de energia elétrica. $\mathrm{O}$ referido julgado corrobora o entendimento de que o art. 22 do CDC não deve ter sua plena aplicação quando diante da falta de contraprestação pecuniária pelo serviço essencial, permitindo que o mesmo não seja mais disponibilizado. Porém, quando não se tratar de caso de inadimplência, a mesma Corte é certa na utilização do art. 22 do Código de Defesa do Consumidor, tratando o Estado como fornecedor ${ }^{16}$.

Retornando à exegese do terceiro artigo do Código de Defesa do Consumidor, verifica-se que no mesmo são elencadas as atividades desempenhadas pelo fornecedor, quais sejam: produção, montagem, criação, construção, transformação, importação, exportação, distribuição ou comercialização de produtos ou prestação de serviços. A partir daí, conclui-se que a prática de fornecer está intrinsecamente

14 TARTUCE, Flávio. Manual de Direito do Consumidor. 3. ed. São Paulo: Método. 2014. p. 91.

15 TJ-SP. APL: 00030004220088260288 SP 0003000-42.2008.8.26.0288, Relator: Ferraz Felisardo, Data de Julgamento: 15/05/2013, 29a Câmara de Direito Privado, Data de Publicação: 15/05/2013

16 TJ-SP. APL: 00027329320128260434 SP 0002732-93.2012.8.26.0434, Relator: Soares Levada, Data de Julgamento: 30/03/2015, 34 Câmara de Direito Privado, Data de Publicação: 31/03/2015 
ligada à atividade desempenhada e o produto ou serviço que é disponibilizado no mercado ${ }^{17}$.

\subsection{Caracterização dos elementos objetivos: produto ou serviço}

O elemento objetivo da relação de consumo é o produto ou serviço comercializado, a título oneroso ou não, em uma relação na qual há um cedente e um recebedor. $\mathrm{O}$ art. $3^{\circ}, \S 1^{\circ}$ do Código de Defesa do Consumidor conceitua produto como "qualquer bem, móvel, imóvel, material ou imaterial".

É importante destacar que a exploração de um valor econômico não é condição imprescindível para que um bem seja caracterizado como produto e consequentemente de possível inserção no microssistema do Código de Defesa do Consumidor ${ }^{18}$. Assim, mesmo que um produto seja distribuído de forma gratuita esta relação estará sujeita à legislação consumerista, ou seja, ainda que não haja onerosidade para o consumidor de imediato, o produto concedido a título de amostra grátis possui valor agregado pelo intuito de despertar no consumidor a vontade de adquiri-lo novamente, desta vez mediante remuneração direta.

É importante frisar ainda que o termo "bem" é mais abrangente que o termo "produto", logo, ao invés de produto o legislador deveria ter utilizado o termo bem, na perspectiva de proporcionar mais abrangência a este elemento da relação de consumo ${ }^{19}$.

No que se refere à característica do produto ser qualquer bem móvel ou imóvel podem ser consideradas as definições do Código Civil. No art. 79 este Diploma legal institui que bem imóvel é o solo e tudo

17 GRINOVER, Ada Pellegrini; et al. Código brasileiro de defesa do consumidor: comentado pelos autores do anteprojeto. 8. ed. Rio de Janeiro: Forense Universitária, 2004. p. 44.

18 ALVES, Fabrício Germano. Proteção Constitucional do consumidor no âmbito da regulação publicitária. Natal: Espaço Internacional do Livro, 2013. p. 61-62.

19 GRINOVER, Ada Pellegrini; et al. Código brasileiro de defesa do consumidor: comentado pelos autores do anteprojeto. $8^{\mathrm{a}}$ ed. Rio de Janeiro: Forense Universitária, 2004, p. 47. 
quanto se lhe incorporar, seja de modo natural ou artificial; e o art. 82 que móveis são bens suscetíveis de movimento próprio ou alheio, sem alteração da substância ou da destinação econômico social. Doutrinariamente considera-se imóvel aquele bem que ao ser transportado ou removido sofre considerável deterioração ou até destruição, e móvel o bem que pode ser deslocado de um ponto a outro sem prejuízos ${ }^{20}$. Nesse sentido, o Direito Civil e das Relações de Consumo caminham juntos na construção do entendimento e características atinentes ao produto como elemento objetivo da relação jurídica de consumo.

Ademais, o legislador no art. $3^{\circ} \S 1^{\circ}$ do CDC cita a característica de que os produtos podem ser tanto materiais quanto imateriais. Consideram-se materiais aqueles com dimensões alcançáveis pelo tato e outros sentidos, e imateriais, aqueles que tenham compreensão oposta. Nesta última categoria estão incluídas as atividades financeiras realizadas nos bancos, que ocorrem em caráter informatizado. Devido à cautela do legislador em instituir um conceito abrangente, o fornecimento desses produtos está submetido à Lei consumerista ${ }^{21}$. Ainda no quesito imaterialidade dos produtos é importante frisar a importância da internet, uma vez que o comércio eletrônico trouxe uma verdadeira revolução quanto à forma de se consumir produtos e serviços ${ }^{22}$.

$\mathrm{O}$ avanço tecnológico permitiu a criação de diversas plataformas de comercialização, assim como de diversos métodos de transferência de dados (v.g., download de músicas, filmes, séries etc.) em que o produto em si é incorpóreo, porém real, consumível, e seus adquirentes ou utilizadores estão albergados pela Lei retro mencionada.

Muito embora o legislador não tenha tratado especificamente no artigo terceiro do $\mathrm{CDC}$ a respeito dos bens duráveis e não duráveis, o

20 TARTUCE, Flávio. Manual de Direito do Consumidor. $3^{\mathrm{a}}$ ed. São Paulo: Método. 2014. p. 81.

21 NUNES, Luiz Antonio Rizzato. Curso de Direito do Consumidor. 7. ed. São Paulo: Saraiva, 2012. p. 141.

22 BLUM, Rita Peixoto Ferreira. Direito do Consumidor na Internet. São Paulo: Quartier, 2002, p. 50. 
artigo 26, incisos I e II ${ }^{23}$, no Capítulo referente à prescrição e decadência, os cita. É considerado durável o produto que não se extingue com o uso, demorando um tempo razoável para que ocorra o desgaste, e não durável, o oposto, com seu uso se extingue, seja em caráter imediato (v.g., um alimento) ou consumativo sequencial (v.g., um sabonete) ${ }^{24}$.

Contudo, é necessário fazer a diferenciação entre um produto não durável e um produto descartável. Apesar dos descartáveis não estarem presentes nas disposições normativas, eles estão presentes no cotidiano, possuindo certa durabilidade, ou seja, seu uso não os extingue imediatamente, porém não há de se falar em constante reutilização dos mesmos, pois são rapidamente, como o próprio nome indica, descartados.

Outrossim, parte da doutrina ${ }^{25}$ acredita que, apesar dos produtos descartáveis não estarem previstos em Lei, eles possuem características mais aproximadas aos produtos duráveis. Sendo assim, por analogia, aos produtos descartáveis são aplicadas as regras e garantias dos produtos duráveis, uma vez que o intuito da norma consumerista é garantir a proteção do consumidor, e diante da inércia legislativa não se pode deixa-lo desamparado.

Outro exemplo de produto não abordado pelo legislador, mas com entendimento já pacificado é o da amostra grátis. O entendimento é que, mesmo inexistindo contraprestação, até porque o dispositivo legal que traz a definição de produto $\left(\mathrm{CDC}\right.$, artigo $\left.3^{\circ}, \S 1^{\circ}\right)$ não a exige, considera-se que o oferecimento de amostra grátis configura uma prática de marketing, que tem finalidade de atrair o consumidor. Sendo assim, a relação na qual o fornecedor oferece amostra grátis está protegida pela legislação consumerista, muito embora não esteja expressamente prevista.

23 Art. 26. O direito de reclamar pelos vícios aparentes ou de fácil constatação caduca em: I - trinta dias, tratando-se de fornecimento de serviço e de produtos não duráveis; II - noventa dias, tratando-se de fornecimento de serviço e de produtos duráveis.

24 NUNES, Luiz Antonio Rizzato. Curso de Direito do Consumidor. 7. ed. São Paulo: Saraiva, 2012. p. 141.

25 Ibid., p. 142. 
$\mathrm{O}$ artigo $3^{\circ}, \S 2^{\circ}$ apresenta uma definição de serviço, segundo a qual assim considera qualquer atividade fornecida no mercado de consumo, por meio de uma contraprestação onerosa, incluindo as de natureza bancária, de crédito, securitária e financeira, com exceção das oriundas das relações de trabalho ${ }^{26}$.

Ao analisar o citado parágrafo, o legislador deixa claro que o serviço deve ser fornecido mediante remuneração, garantindo onerosidade à relação, no entanto, é admitido que hajam vantagens indiretas para prestador do serviço, sem que descaracterize a relação de consumo ${ }^{27}$. É o caso clássico dos estacionamentos gratuitos de shopping centers que, apesar de gratuitos, são oferecidos como um chamariz de consumidores, gerando indiretamente lucros ao estabelecimento.

Ademais, como rol exemplificativo, a legislação menciona as atividades de natureza bancária (v.g., os contratos de conta corrente, conta poupança, depósitos bancários etc.), financeira, de crédito e securitária. Por se tratar de negócios financeiros, o contrato de cartão de crédito é protegido pela Lei Federal no 8.078/90, sendo os seus sujeitos, o titular do cartão e o banco ou empresa que explora esse tipo de serviço ${ }^{28}$. Estão listados também os serviços securitários, como o caso de um seguro de automóvel, assim como os contratos de plano de saúde por força da Súmula 469 do STJ $^{29}$.

\subsection{Identificação do destinatário final}

Para configuração da relação de consumo o legislador impõe que consumidor deve ser destinatário final de um produto ou serviço. Em contrapartida, a aquisição dos elementos objetivos ora citados com ob-

26 Art. $3, \S 2^{\circ}$. Serviço é qualquer atividade fornecida no mercado de consumo, mediante remuneração, inclusive as de natureza bancária, financeira, de crédito e securitária, salvo as decorrentes das relações de caráter trabalhista.

27 TARTUCE, Flávio. Manual de Direito do Consumidor. 3. ed. São Paulo: Método. 2014. p. 84.

28 Ibid., p. 85.

29 Superior Tribunal De Justiça. Súmula $n^{\circ} 469$. Aplica-se o código de defesa do consumidor aos contratos de plano de saúde. 
jetivo de os incluir em uma cadeia de produção, não configura consumo, mas sim uma relação de intermediação que se opera dentro de um ciclo em relação ao qual não se aplica a normatização consumerista.

Contudo, a terminologia "destinatário final" utilizada pelo legislador gera discussões a respeito da aplicação ou não da Lei consumerista no caso da aquisição de um produto ou serviço com intuito da utilização como típico bem de produção ${ }^{30}$. A Lei Federal n ${ }^{\circ}$ 8.078/90 foi silente quanto aos bens de produção e consumo, fazendo com que a conceituação de consumidor seja limitada devido justamente à terminologia destinatário final.

Apesar disso, uma linha de raciocínio é capaz de dirimir tal impasse de aplicação ou não da Lei consumerista no caso mencionado. Em se tratando da aquisição de típicos bens de produção não pode haver aplicação do CDC porque não está inserida nas finalidades dessa norma a proteção da relação de aquisição desses bens. Além disso, o protecionismo $^{31}$ e as restrições decorrentes da incidência da legislação consumerista podem vir a se tornar um entrave para o desdobramento das relações comerciais.

Por outro lado, é cristalina a preocupação do CDC quanto aos bens típicos de consumo, uma vez que estes são fabricados e inseridos no mercado de consumo por meio de diversas formas. Nesse caso não há impasse quanto à aplicação da Lei Federal n ${ }^{\circ} 8.078 / 90$, sendo essa imediata quando diante dos requisitos já esclarecidos no presente texto.

Ademais, a menção a "destinatário final" que o artigo $2^{\circ}$ do CDC utiliza para caracterização de consumidor está relacionada à utilização do bem ou serviço, que deve ser particular, seja individual ou familiar, ou até mesmo para benefício de terceiros, porém sem intuito de revenda, montagem ou industrialização ${ }^{32}$. Assim, é possível afirmar que a destinação final é característica intrínseca à figura do consumidor.

30 NUNES, Luiz Antonio Rizzato. Curso de Direito do Consumidor. 7. ed. São Paulo: Saraiva, 2012. p. 122.

31 Ibid., p. 125.

32 ALMEIDA, João Batista de. Manual de Direito do Consumidor. São Paulo: Saraiva, 2003, p. 37-38. 


\section{REgulamentAÇÃo do DIREITO DE ARREPENDIMENTO}

Para a análise do tema ora desenvolvida mostra-se imprescindível a realização de uma abordagem da sua regulamentação no ordenamento jurídico brasileiro, com foco nas limitações existentes e futuras.

\subsection{Direito de arrependimento no Brasil}

Na normativa brasileira o direito de arrependimento está explicito em apenas um artigo (art. 49, CDC), com poucos requisitos e sem maiores esclarecimentos, restando à doutrina e jurisprudência tal papel diante da incompletude legislativa e das possibilidades de interpretação do mesmo.

No artigo 49 do CDC são dois os requisitos para que o consumidor possa exercitar o direito de se arrepender gratuitamente: fazê-lo em sete dias e ter comprado o produto fora do estabelecimento comercial.

O direito de arrependimento é potestativo e, consequentemente, sujeito a prazos decadenciais. O Código Civil somente permite a suspensão de prazos decadenciais em casos específicos, como o do art. 26, $\S 2^{\circ}$ do $\mathrm{CDC}$, isto é, quando diante de reclamação de vício aparente ou de fácil constatação ${ }^{33}$. O prazo de sete dias é contado na forma corrida, como determina o artigo 132 do Código Civil ${ }^{34}$.

Outro requisito para exercício do direito de arrependimento é a aquisição do produto fora do estabelecimento comercial. Por esse quesito é possível adotar interpretação extensiva a qual inclui a internet, telefone, vendas em domicilio, entre outras que impossibilitam o consumidor de fazer um juízo de valor claro do objeto ou serviço adquirido, tal qual faria se estivesse pessoalmente.

33 GOMIDE, Alexandre Junqueira. Direito de Arrependimento nos Contratos de Consumo. 1. ed. São Paulo: Almeida, 2014. p. 60.

34 Art. 132. Salvo disposição legal ou convencional em contrário, computam-se os prazos, excluído o dia do começo, e incluído o do vencimento. $\S \mathbf{1}^{\circ}$ Se o dia do vencimento cair em feriado, considerar-se-á prorrogado o prazo até o seguinte dia útil. $\S 2^{\circ}$ Meado considera-se, em qualquer mês, o seu décimo quinto dia. $\S \mathbf{3}^{\circ}$ Os prazos de meses e anos expiram no dia de igual número do de início, ou no imediato, se faltar exata correspondência. 
No entanto, há uma interpretação no sentido de que o disposto no art. 49 do CDC não deveria ser aplicado nos casos em que o consumidor visita o estabelecimento comercial virtual do fornecedor, por acreditar ser uma iniciativa daquele, encontrando-se na mesma situação de quem se dirige ao estabelecimento físico. Nestes casos, então, seria possível a aplicação do direito de arrependimento apenas na hipótese de $m a$ rketing agressivo ${ }^{35}$, situação a qual caberia a resolução contratual por descumprimento do contrato ${ }^{36}$ por quebra da boa-fé.

Tal pensamento torna-se equivocado já que, muito embora tenha sido uma procura do consumidor, nada impede que este seja iludido ou convencido por ofertas relâmpagos ou falta de informações a respeito do produto que resultem em uma aquisição indesejada. A expressão "fora do estabelecimento comercial" faz referência à ausência do ambiente físico do fornecedor, e consequentemente à distância do objeto da transação, o que impossibilita um juízo de valor mais apurado a respeito do produto adquirido.

Ademais, no período em que o bem se encontra sob posse do consumidor, denominado "período de reflexão", é seu dever salvaguarda-lo até a data limite de sua devolução, caso esse seja o seu desejo. A boa-fé do consumidor que exerce o direito de arrependimento resta configurada quando este retorna o objeto para a caixa e o devolve nas mesmas condições em que adquiriu ${ }^{37}$. No entanto, caso haja qualquer tipo de desvalorização do bem por mau uso do próprio consumidor, o fornecedor deverá ser indenizado.

Mais adiante, o parágrafo primeiro do art. 49 do CDC determina que quando for exercido o direito de arrependimento os valores pagos deverão ser devolvidos de imediato e monetariamente atualizados. Quanto à restituição atualizada a que se refere o legislador, deve-se levar em consideração que o Código foi formulado em uma época da economia brasileira na qual a inflação era muito oscilante, tornando

35 GOMIDE, Alexandre Junqueira. Direito de Arrependimento nos Contratos de Consumo. 1. ed. São Paulo: Almeida, 2014. p. 128.

36 Ibid. p. 124

37 Ibid., p. 126. 
possível uma diferença considerável entre um dia e outro, contudo atualmente a economia está mais estabilizada, sendo assim, se o fornecedor restituir o valor em um período razoável não há de se falar em necessidade de atualização ${ }^{38}$. Entretanto, caso o fornecedor de fato demore muito a restituir o consumidor, aquele incorre em mora, cabendo, além da devolução do valor pago, juros de mora mais e perdas e danos, conforme art. 389 do Código Civil ${ }^{39}$.

A análise quanto à natureza jurídica do direito de arrependimento provoca divergências, uma vez que possui características mescladas de alguns institutos da extinção contratual, sendo uma forma de extinção contratual com efeito retroativo, sem a existência de indenização. Os tipos de extinção são: resolução, resilição e rescisão.

Por resolução o contrato é extinto devido à inexecução do avençado ou por não cumprimento das obrigações por um dos contraentes, podendo ser voluntária ou involuntária. A voluntária é quando há conduta culposa que cause prejuízo à outra parte, a extinção contratual tem efeito ex tunc, e há restituições recíprocas. A involuntária ocorre quando não há culpa dos envolvidos, podendo se dar por terceiros ou por ação inevitável, caso fortuito ou de força maior. Nesta não há indenização, salvo se essa possibilidade estiver contratualmente expressa ${ }^{40}$.

Outra forma de extinção contratual é a resilição, que advém da demonstração de vontade de uma das partes (unilateral) ou das duas partes (bilateral), sendo esta chamada de "distrato". A primeira, só pode ocorrer em determinados tipos de contrato, pois a regra geral dos contratos é contrária a essa possibilidade de rompimento do vínculo por vontade exclusiva de uma das partes ${ }^{41}$.

38 Ibid., p. 126.

39 Art. 389. Não cumprida a obrigação, responde o devedor por perdas e danos, mais juros e atualização monetária segundo índices oficiais regularmente estabelecidos, e honorários de advogado.

40 GONÇALVES, Carlos Roberto. Direito Civil brasileiro: contratos e ato unilaterais. 8. ed. São Paulo: Saraiva, 2011, v. 3, p.185 e 204.

$41 \quad$ Ibid., p. 204. 
A rescisão, por sua vez, é a extinção do contrato quando diante de uma situação de lesão ou perigo, isto é, por um defeito no negócio jurídico no que tange aos pressupostos de existência, validade e eficácia ou diante de uma situação em que o contrato fora celebrado independente de juízo de valor, no intuito de mitigar um iminente perigo.

Portanto, o direito de arrependimento não se trata de resolução, já que não há de se falar em inexecução contratual, ele é perfeito, porém por vontade subjetiva é desfeito. Também não se trata de resilição, já que, apesar da existência da vontade de uma das partes em findar o avençado, não se trata de um direito ou regra, mas de uma exceção, enquanto o direito de reflexão é um direito concedido ao consumidor. E, por fim, não é rescisão, já que não se está diante de uma situação de lesão propriamente dita e nem de situação de perigo.

Sendo assim, é possível afirmar que a natureza jurídica do direito de arrependimento é sui generis ao qual se aproxima efetivamente de uma forma de resilição unilateral, que na falta de regras próprias segue o regime da resolução contratual, sendo em exercício uma resilição e em consequência uma resolução ${ }^{42}$.

\subsection{Limitações ao direito de arrependimento}

$\mathrm{Na}$ atual normativa que institui e regulamenta o direito de arrependimento poucas são as limitações. A primeira delas se refere ao prazo para o exercício desse direito, que é de sete dias úteis. A segunda é quanto ao local, restringindo-se às compras realizadas fora do estabelecimento, e por fim, como última limitação presente, apesar de não explícito no teor do art. $49 \mathrm{CDC}$, é a do não abuso do direito.

O abuso de direito está positivado no artigo 187 do Código Civil, que aduz: "também comete ato ilícito o titular de um direito que, ao exercê-lo, excede manifestamente os limites impostos pelo seu fim econômico ou social, pela boa-fé ou pelos bons costumes". Então, todo detentor de direito que exceder sua aplicação, seja em caráter

42 GOMIDE, Alexandre Junqueira. Direito de Arrependimento nos Contratos de

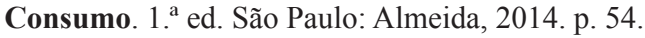


econômico, social, ou em desrespeito aos princípios da boa-fé e dos bons costumes, comete abuso de direito (ato ilícito). O Código de Defesa do Consumidor consagrou no art. $6^{\circ}$, inciso IV como um dos direitos básicos do consumidor "a proteção contra a publicidade enganosa e abusiva, métodos comerciais coercitivos ou desleais, bem como contra práticas e cláusulas abusivas ou impostas no fornecimento de produtos e serviços".

Assim, as referidas disposições normativas aparecem como instrumentos do Direito para restabelecer o equilíbrio nas relações contratuais, bem como a força da "vontade, das expectativas legitimas, do consumidor, compensando, assim, sua vulnerabilidade fática, assim como as normas sobre clausulas e práticas abusivas ${ }^{43}$. Torna-se assim, a previsão de não abusividade contra o consumidor, um direito básico essencial para a justiça nas relações de consumo.

Tal entendimento pode ser visto em julgado do Tribunal de Justiça do Distrito Federal ${ }^{44}$ no qual a consumidora foi condenada a indenizar o fornecedor com fundamento no abuso do direito de reclamar. Na lide em questão a consumidora não ficou satisfeita com um posicionamento do fornecedor e decidiu por utilizar a internet não somente para expor seu pensamento crítico, mas também com o intuito de atingir a honra objetiva da empresa, isto é, a reputação e imagem desta perante atuais e futuros consumidores.

Sendo assim, pode-se afirmar que, no art. 49 do CDC, juntamente com o art. 187 do Código Civil e o princípio da boa-fé, são encontradas as principais limitações atuais que o direito de arrependimento possui. Estas limitações são bastante úteis para manter o equilíbrio nas relações consumeristas, caso isso não seja possível por estes meios, cabe ao Poder Judiciário o cumprimento de tal papel.

43 BENJAMIN, Antonio Herman V et al. Manual de Direito do Consumidor. 6. ed. São Paulo: Revista dos Tribunais, 2014. p. 80.

44 Tribunal de Justiça do Distrito Federal. TJ-DF. APC: 20140111789662, Relator Hector Valverde Santanna, Data de Julgamento: 09/09/2015. 6 a Turma Cível, Data de Publicação: Publicado no DJE 28/07/2015. 


\subsection{Projeto de Lei do Senado n. 281/2012 e o Decreto}

\section{N. $7.962 / 2013$}

A partir da análise dos textos do Decreto $n^{\circ} 7.962 / 2013$ e do Projeto de Lei do Senado n ${ }^{\circ}$ 281/2012 é possível notar que há compreensões e entendimentos correlatos ou até iguais, tendo os textos sido propostos em anos subsequentes, 2012 para a PLS e 2013 para o Decreto Federal.

O Decreto $n^{0} 7.962 / 2013$ foi produzido com o fim de regulamentar a Lei Federal $n^{\circ}$ 8.078/90 (Código de Defesa do Consumidor) quanto às aquisições realizadas no comércio eletrônico e traz algumas definições importantes acerca do direito de arrependimento. Já o Projeto de Lei do Senado $\mathrm{n}^{\mathrm{o}} 281$, que atualmente encontra-se encaminhado para aprovação da Câmara dos Deputados ${ }^{45}$, foi criado com o intuito de atualizar o Código de Defesa do Consumidor para adequá-lo às práticas comerciais atuais, mantendo o objetivo primordial da Lei consumerista que é de proteger o consumidor.

A primeira similaridade entre os textos ocorre entre o art. $2^{\circ}$ do Decreto $n^{\circ} 7.962 / 2013$ e o art. 44-B do PLS 218/2012. Ambos possuem escrita idêntica no sentido de tornar obrigatório que os sítios eletrônicos informem dados como nome empresarial e número de inscrição em órgão regulamentador, endereço físico, características essenciais do produto, condições e restrições da oferta.

Em seguida, há congruência entre os textos do art. $4^{\circ}$ do Decreto em análise com o art. 44-D do Projeto de Lei do Senado. Ambos possuem texto igual, porém em ordenação diferente, que determina que o fornecedor deve apresentar sumário do contrato antes da contratação, tornando o consumidor ciente das informações necessárias ao pleno exercício do direito de escolha, destacando aquelas que restringem direitos. Além disso, deve também o fornecedor: manter canal que possibilite ao consumidor enviar e receber informações, confirmar o recebimento de comunicações; assegurar ao consumidor os meios técnicos adequados, eficazes e acessíveis que possibilitem a identificação

45 Disponível em: $<$ https://www25.senado.leg.br/web/atividade/materias/-/materia/106768>. Acesso em: 11 jul. 2016. 
e eventual correção das informações antes de finalizar a contratação, sem prejuízo do exercício do direito de arrependimento; além de utilizar mecanismos de segurança para pagamento e tratamento de dados do consumidor.

No entanto, os dispositivos divergem em alguns pontos. $\mathrm{O}$ art. $4^{\circ}$ do Decreto, nos incisos IV e VI, respectivamente, informa ser obrigação do fornecedor disponibilizar o contrato ao consumidor em meio capaz de conservação e reprodução imediatamente após a contratação, e confirmar o recebimento imediato das demandas do consumidor pelo mesmo meio utilizado para a contratação. $O$ parágrafo único do referido dispositivo, que não possui equivalente no Projeto de Lei, determina que as manifestações do fornecedor em relação às demandas do consumidor deverão ser encaminhadas a este último em até 5 dias.

Já o Projeto de Lei do Senado no 281/2012 não inspirou a redação do Decreto 7.962/2013 nos incisos VI e VII do art. 44-D. O primeiro propõe tratar como obrigação do fornecedor informar aos órgãos de defesa do consumidor e ao Ministério Público, quando requisitado, nome, endereço eletrônico, e outros dados capazes de identificar o contrato do provedor de hospedagem, bem como os prestadores de serviços financeiros e de pagamento. O segundo, por sua vez, busca tornar o fornecedor obrigado a informar imediatamente às autoridades competentes e ao consumidor sobre o vazamento de dados ou comprometimento da segurança do sistema. Ressalta-se que o Decreto em vigor apenas obriga o fornecedor a prezar pela segurança dos dados, porém não dá qualquer direcionamento caso o contrário ocorra. Essa segunda hipótese é proposta no PLS de 2012 mas não foi incorporada ao Decreto de 2013, embora vários outros termos tenham sido.

Outro conteúdo convergente refere-se ao direito de arrependimento. $\mathrm{O}$ art. $5^{\circ}$, caput do Decreto possui conteúdo e termos parecidos com o art. 49, $\S 8^{\circ}$ do PLS 281/2012, na medida em que obriga o fornecedor a informar de maneira clara os meios disponíveis para exercício do direito de arrependimento. $\mathrm{O}$ art. $5^{\circ}, \S 3^{\circ}$ do Decreto $n^{\circ} 7.962 / 2013$ possui redação convergente com o art. 49, $\S 6^{\circ}$ do PLS 281/2012, que institui como regra a obrigação de o fornecedor comunicar à instituição 
financeira ou administradora, assim que for exercido o direito de arrependimento, para que a transação não seja lançada na fatura do consumidor, sendo efetivado o estorno do valor. Caso o lançamento já tenha ocorrido, no Projeto de Lei há a previsão de que, caso o preço já tenha sido total ou parcialmente pago, deverá ser lançado o respectivo crédito na fatura a ser emitida posteriormente à comunicação.

Por fim, é possível inferir a semelhança existente entre o conteúdo do art. $5^{\circ}, \S 4^{\circ}$ do Decreto e o do art. 49, $\S 9^{\circ}$ do PLS 281/2012, na medida em que ambos obrigam o fornecedor a enviar ao consumidor imediata confirmação do recebimento da manifestação do arrependimento.

Sendo assim, os textos possuem diversas similaridades de conteúdo, porém foram propostos de formas diferentes e em anos subsequentes. O PLS n ${ }^{\circ} 281 / 2012$, sem dúvidas, serviu de modelo para o Decreto $n^{0} 7.962 / 2013$, que logo pôde ser aplicado na proteção do consumidor. Embora possua inovações robustas e extremamente importantes para a defesa do consumidor, o Projeto de Lei do Senado ainda prescinde de aprovação para que possa surtir efeitos na prática.

\section{Direito de ARREPENDIMETO DE PRODUtos PERSONALIZAdos NA JURISPRUDÊNCIA}

O texto do art. 49 do Código de Defesa do Consumidor vigente não traz qualquer limitação ao direito de arrependimento. No mesmo sentido é a regulamentação posterior feita pelo Decreto no 7.962/2013. A única exceção é proposta no PLS 281/2012, em seu art. 49-A, que sugere que o exercício do direito de arrependimento na aquisição de passagens aéreas tenha prazo diferenciado devido a peculiaridade do contrato a ser regulamentado por disposição normativa proveniente de agências reguladoras.

Quanto aos produtos personalizados, muito embora tenha sido proposta a limitação de aplicação do direito de arrependimento na compra dos mesmos na Emenda $n^{\circ}$ 26, pelo Senador Antônio Carlos Rodrigues para o Projeto de Lei do Senado 281/2012, a Comissão Temporária de Modernização do Código de Defesa do Consumidor não aprovou total- 
mente a referida Emenda, sob o argumento de que tal limitação seria antifuncional e até abusiva, acolhendo apenas a possibilidade de restrição ao direito de se arrepender na aquisição de bilhetes aéreos.

Há na doutrina entendimento no sentido de que consumidor se arrepender de uma compra feita sob encomenda parece uma injustiça ao fornecedor, não podendo tal situação ser encarada como risco inerente ao negócio, abrindo caminho para abuso de direito pelo consumidor ${ }^{46}$. Pelo princípio da boa-fé o arrependimento de produto personalizado seria indevido e deveria ter limitação expressamente prevista no ornamento jurídico. Tal raciocínio também é pautado no princípio da boa-fé e não vislumbra possibilidade de aplicação do direito de arrependimento quando da aquisição de produtos personalizados, no entanto vê como exceção os casos em que a reclamação estiver pautada em eventual vício do produto fabricado ${ }^{47}$.

Já a jurisprudência segue a interpretação da Lei Federal no 8.078/90, não absorvendo possibilidade de limitação ao direito de arrependimento na compra de produtos personalizados, uma vez que não há previsão legal. Assim foi o argumento utilizado pelo Tribunal de Justiça do Distrito Federal $(\mathrm{TJDF})^{48}$, em caso que diz respeito à aquisição de fotografias com arrependimento posterior realizado no prazo legal. Entendeu a supracitada Corte que o direito de arrependimento previsto no art. 49 do CDC não está condicionado à natureza do produto adquirido, e que o fato de ser produto personalizado não extirpa do consumidor o direito de se arrepender, desde que este direito seja exercido no período legal e a aquisição tenha sido realizada fora do estabelecimento comercial. No voto, a Relatora afirma ainda que a estratégia da venda em domicílio está sujeita aos riscos do negócio, ainda que a desistência por parte do

46 GOMIDE, Alexandre Junqueira. Direito de Arrependimento nos Contratos de Consumo. 1. ed. São Paulo: Almeida, 2014. p. 127.

47 MARQUES, Cláudia Lima. Contratos no Código de Defesa do Consumidor: o novo regime das relações contratuais. 4. ed. São Paulo: Revista dos Tribunais, 2002. p. 719.

48 Tribunal de Justiça do Distrito Federal. TJ-DF - ACJ: 20151010013067, Relator: Oriana Piske, Data de Julgamento: 06/10/2015. 2a Turma Recursal dos Juizados Especiais do Distrito Federal, Data de Publicação: Publicado no DJE 08/10/2015. p. 293. 
consumidor torne o produto imprestável para nova negociação, como no caso de álbum de fotografias, que é o objeto de que trata a ação ${ }^{49}$.

O Tribunal de Justiça do Mato Grosso (TJMG) corroborou o posicionamento do TJDF ao decidir que a alegação de um produto ser especial, isto é, sob encomenda não serve para desnaturar a relação de consumo, tampouco suplantar o direito de arrependimento, uma vez que "tais circunstâncias não descaracterizam a relação de consumo que marcou a transação, não passando de risco próprio e natural da atividade mercantil do ramo de negócio abraçado livremente pela apelante" 50 .

Assim, muito embora haja na doutrina autores que não reconhecem a aplicação do direito de arrependimento a produtos personalizados $^{51}$, a jurisprudência ${ }^{52}$ interpreta a legislação de modo a não absorver tal limitação, tornando possível que um consumidor que tenha contratado um produto sob suas especificações se arrependa da aquisição e tenha o montante pago devolvido, desde que o faça no prazo decadencial legal de sete dias e que a compra tenha sido realizada fora do estabelecimento comercial.

Apesar de a devolução de um produto personalizado ser, de fato, capaz de acarretar ônus ao fornecedor, já que é muito improvável que tal produto seja revendido para outro consumidor, aquele que contratou à distância o produto bem como sua personalização foi incapaz de ter contato com o mesmo antes da efetiva contratação, de maneira que pudesse realizar um juízo mais consistente e assim ter total certeza de sua aquisição, da maneira que ocorre com todos os produtos adquiridos diretamente dentro do estabelecimento comercial.

$49 \quad$ Ibid., p. 293.

50 Tribunal de Justiça do Mato Grosso. TJMT - AC 24.068 - CLASSE II - 23 - POCO$N E ́$ - $3^{a}$ C. CÍV. - Rel. Des. José Ferreira Leite - J. 28.06.2000.

51 GOMIDE, Alexandre Junqueira. Direito de Arrependimento nos Contratos de Consumo. 1. ed. São Paulo: Almeida, 2014. p.127

52 Tribunal de Justiça do Distrito Federal. TJ-DF - ACJ: 20151010013067, Relator: Oriana Piske, Data de Julgamento: 06/10/2015. $2^{\text {a }}$ Turma Recursal dos Juizados Especiais do Distrito Federal, Data de Publicação: Publicado no DJE: 08/10/2015. p.293 e Tribunal de Justiça do Mato Grosso. TJMT. AC 24.068. CLASSE II. 23 POCONÉ. $3^{a}$ C. CÍV. Rel. Des. José Ferreira Leite - DJ. 28.06.2000. 
Limitar o direito de arrependimento do consumidor em relação a um produto personalizado é torna-lo refém de possíveis abusos do fornecedor, uma vez que este, por ter contato com o produto que comercializa sabe o que irá vender, mas nem sempre o consumidor é capaz de absorver de maneira satisfatória as informações cedidas no momento da compra.

Para sustentar o posicionamento contrário à aplicação do direito de arrependimento aos produtos personalizados enseja-se que tal limitação seria importante para evitar a má-fé e o abuso de direito ${ }^{53}$. Contudo, obrigar o consumidor permanecer com um produto que não lhe foi oportunizado fazer uma análise mais detalhada a fim de conhecer as suas reais características parece um contrassenso. Isso porque é possível que ocorra má-fé e abuso de direito por pare do próprio fornecedor em razão de um problema interno de comunicação (v.g., erro de grafia do nome do consumidor). Nesse sentido, no entanto, entende-se ser admitido o direito de arrependimento para produtos personalizados apenas quando eivados de vício ${ }^{54}$, porém atribuir análise subjetiva à aplicação do direito de arrependimento parece gerar conflitos jurídicos, além de ser inerente o fato de o consumidor ter de motivar a devolução do produto sob encomenda, questão que não é trazida como requisito no art. 49, caput do CDC.

A Lei Federal $n^{\circ}$ 8.078/90 foi sancionada para defender o consumidor dos modelos agressivos de comércio, neste mesmo desiderato foram elaborados o PLS 281/2012 e o Decreto 7.962/2013. De tal forma, anular um direito que tanto protege o consumidor de ofertas agressivas, informações não apresentadas ou insuficientes, dentre outras práticas danosas parece não ser a melhor opção e pode ser até mesmo um fator ensejador de situações de abuso de direito por parte do fornecedor.

53 GOMIDE, Alexandre Junqueira. Direito de Arrependimento nos Contratos de Consumo. 1. ed. São Paulo: Almeida, 2014. p. 79.

54 MARQUES, Cláudia Lima. Contratos no Código de Defesa do Consumidor: o novo regime das relações contratuais. 4. ed. São Paulo: Revista dos Tribunais, 2002. p. 719. 
Além disso, caso fosse posta em prática a limitação proposta na Emenda $n^{\circ} 26$ pelo Senador Antônio Carlos Rodrigues perante o PLS $281 / 2012$, que embora defendida por parte da doutrina ${ }^{55}$ não foi acatada, poderia gerar um desencorajamento do consumidor para a contratação de serviços personalizados por meio do comércio eletrônico. Este tipo de serviço tem grande valor agregado, justamente pela personalização, o que o faz ser comercializado a um preço mais alto que os produtos convencionais. O não fornecimento do mesmo poderia acarretar prejuízo para os seus fornecedores.

Sendo assim, é possível afirmar que, no geral, a limitação ao direito de arrependimento do consumidor que contrata fora do estabelecimento comercial um produto personalizado traz mais malefícios do que benefícios. Em caso de constatação de abuso de direito e/ou má-fé por parte do consumidor em detrimento do fornecedor, o Poder Judiciário pode e deve ser acionado para dirimir tal questão e tornar a relação equânime.

Ademais, diante da atual conjuntura econômica do Brasil, na qual enfrenta grave recessão ${ }^{56}$, é importante que haja valorização do consumidor para que seja retomada a saúde financeira do país. A desconfiança dos consumidores, mesmo que em relação a uma única categoria de produto (os personalizados), já seria capaz de diminuir em certa monta o volume de transações financeiras. Isso deve ser considerado principalmente porque uma grande parte da aquisição de produtos personalizados e feita pelo comércio eletrônico, que é um campo de utilização em larga escala atualmente e que, mesmo em um momento de crise econômica vivenciada no país, tem projeções de crescimento ${ }^{57}$.

Considerando as consequências da sensação de desvalorização do consumidor na situação de resseção econômica que o Brasil se encon-

55 GOMIDE, Alexandre Junqueira. Direito de Arrependimento nos Contratos de Consumo. 1. ed. São Paulo: Almeida, 2014. p. 127.

56 Brasil está 'mergulhado' em recessão profunda, diz FMI. Disponível em $<$ http:// g1.globo.com/economia/noticia/2016/04/brasil-esta-mergulhado-em-recessao-economica-profunda-diz-fmi.html>. Acesso em: 14 jul. 2016.

57 Comércio eletrônico deve crescer $18 \%$ e faturar R\$ 56,8 bi em 2016. Disponível em <http:/g1.globo.com/economia/noticia/2016/01/comercio-eletronico-devecrescer-18-e-faturar-r-568-bi-em-2016.html>. Acesso em: 14 jul. 2016. 
tra, bem como o impacto negativo da limitação do direito de arrependimento, não se vislumbra tal possibilidade de mitigação em relação aos produtos personalizados especificamente. Em qualquer relação jurídica deve pairar o princípio da boa-fé e o não abuso de direito. O receio exacerbado deste último poderia impossibilitar a ocorrência de infinitas relações no âmbito do Direito, sendo tal argumento ínfimo diante da proteção que o direito de arrependimento proporciona ao consumidor de produtos em geral, incluindo os personalizados.

\section{Conclusão}

$\mathrm{O}$ art. 49 do CDC prevê como direito do consumidor o arrependimento de compras e a consequente devolução do bem e do quantum valorativo pago desde que preenchidos os requisitos legais: prazo de até sete dias úteis a partir do recebimento e o fato da compra ter se realizado fora do estabelecimento comercial.

Atendidos esses requisitos, o exercício do direito de arrependimento causa a extinção contratual. Esta possui uma natureza jurídica sui generis, uma vez que se aproxima de uma forma de resilição unilateral, mas que por outro lado segue o regime da resolução contratual. Deste modo, pode-se afirmar que em relação ao exercício consiste em uma resilição e à consequência, em uma resolução.

$\mathrm{O}$ direito de arrependimento atualmente é muito exercido nas transações realizadas por meio do comércio eletrônico. Na realidade, nesta forma de contratação, as partes e o objeto da contratação não ocupam simultaneamente o mesmo ambiente físico. Essa peculiaridade é capaz de comprometer seriamente o julgamento adequado acerca da qualidade e oportunidade da negociação. Além disso, em tais condições o consumidor encontra-se muito mais suscetível a influências psicológicas capazes de fazê-lo tomar uma decisão por impulso.

Em razão da complexidade do mercado de consumo, apesar de inúmeras disposições do Código de Defesa do Consumidor serem alvo de discussão permanente, ainda persistem muitas divergências interpretativas que problematizam a sua aplicação prática. Em 2012, foi instau- 
rada no Senado Federal uma comissão responsável pela atualização do CDC com a finalidade de acompanhar o desenvolvimento do mercado de consumo e propor mudanças legislativas que possibilitassem atingir o objetivo da criação do Código, que consiste na regulação das relações de consumo com especial proteção do consumidor.

Dentre as propostas de atualização do Projeto de Lei do Senado ${ }^{\circ}$ 281/2012 encontra-se a modificação do art. 49 do CDC, referente ao direito de arrependimento. Apesar de ainda estar em tramitação, o Documento prevê a criação de nove parágrafos a fim de regulamentar o dispositivo. No texto existem diversas inovações, tais como: a explicação do legislador sobre o que compreende compra fora do estabelecimento comercial, uma previsão de tratamento diferenciado quanto ao prazo do direito de arrependimento na compra de passagens aéreas, a obrigação do fornecedor em informar quais meios deverão ser utilizados pelo consumidor para praticar o direito de arrependimento, dentre outras.

Entretanto, ciente da necessidade imediata de formação de uma compreensão uníssona sobre o tema, a Presidência da República editou

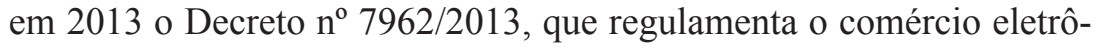
nico à luz do CDC. Neste Diploma normativo foram estipulados alguns deveres para o fornecedor que se relacionam diretamente com o direito de arrependimento. Dentre eles destacam-se: a) informar, de maneira clara e ostensiva, os meios adequados e eficazes para o exercício do direito de arrependimento pelo consumidor; b) disponibilizar a mesma ferramenta utilizada para a contratação para o exercício do direito de arrependimento; c) comunicar imediatamente a instituição financeira ou a administradora do cartão de crédito ou similar, para que a transação não seja lançada na fatura do consumidor, ou para que seja efetivado o estorno do valor, caso o lançamento na fatura já tenha sido realizado; e d) enviar ao consumidor confirmação imediata do recebimento da manifestação de arrependimento.

Algumas partes do texto do Decreto em muito se assemelham em conteúdo e terminologia ao Projeto de Lei do Senado, contudo, pela necessidade de tramitação nas duas casas do Congresso Nacional, bem como de ser sancionado pela Presidência da República, a atualização que 
viria a partir do referido Projeto permanece apenas como uma necessidade que vem sendo suprida somente em parte pelo mencionado Decreto.

Atualmente, uma das questões que mais deixa dúvidas em relação ao exercício do direito de arrependimento é a sua limitação. Nesse contexto, na edição do PLS 281/2012 buscou-se, pela Emenda n ${ }^{\circ} 26$, incluir no artigo 49 do CDC um parágrafo que permitisse a limitação do direito de arrependimento no sentido de impedir que ele seja praticado para aquisição de alguns produtos, dentre os quais encontram-se os que são fabricados a partir de especificação do consumidor (personalizados). No entanto, a presidência da Comissão acertadamente não aprovou essa possibilidade de limitação, sob o argumento de que implicaria em uma diminuição de direitos do consumidor, que não faz parte do objetivo principal do Projeto.

Da atual redação do dispositivo do direito de arrependimento, nada se fala a respeito de limitação a arrepender-se (Com exceção de no PLS 281/12 prever limitação do direito de arrependimento na compra de passagens aéreas), isto é, a natureza do produto em nada interfere no direito do consumidor que o adquiriu fora do estabelecimento e o praticou em sete dias contatos a partir do contato com o objeto, e apesar de silente a normativa atual, restringir um direito do consumidor pautado no tipo de produto, como um produto personalizado, é injusto, uma vez que esse consumidor está sujeito às mesmas impossibilidades de juízo de valor quanto a qualidade e consonância com as informações dadas pelo fornecedor e práticas comerciais abusivas como em relação a qualquer outro produto.

Partindo desse pressuposto, muito embora a devolução de um produto confeccionado sob os gostos do consumidor que utilizou como meio o comércio eletrônico para tal contrato seja capaz de gerar um ônus ao fornecedor, devido à possível inaplicabilidade de revenda deste, ao consumidor por sua vez não foi oportunizado fazer juízo de valor a respeito da qualidade do que foi contratado como em qualquer outra aquisição fora do estabelecimento comercial. Devendo, então, esse ônus ser suportado pelo fornecedor que optou por essa forma de comércio. 
Ademais, a iminência de abuso de direito e ferimento ao princípio da boa-fé não devem ser utilizados como argumento, uma vez que ao diminuir o direito do consumidor o mesmo perigo permanece já que o fornecedor é hipersuficiente quando em relação ao consumidor que passa a creditar nas informações fornecidas por ele, que por vezes podem ser insuficientes.

E para impedir tais perigos, de abuso de direito e ferimento ao princípio da boa-fé, o Código de Defesa do Consumidor e o Código Civil já permitem considerar a ilicitude de tais práticas. E mesmo que elas ocorram há previsão de sanções. Ou seja, com a não previsão de limite ao direito de arrependimento para os produtos personalizados fica o consumidor protegido de práticas abusivas de comércio, de incoerência de informações e de vícios de qualidade e da vedação a abuso de direito, e o fornecedor, por sua vez, está respaldado quando da ocorrência de tais questões devido as compreensões gerais tanto do CDC, quanto do CC.

Sendo assim, nas compras realizadas sob o contexto do comércio eletrônico mesmo que personalizadas deve o consumidor poder se arrepender no prazo decadencial de sete dias, possibilitando-o quando em contato com o bem ora contratado fazer juízo de valor de qualidade, adequação e oferta que não lhe foi permitido inicialmente pela natureza do contexto da contratação, qual seja, comércio eletrônico.

\section{REFERÊNCIAS}

ALMEIDA, João Batista de. Manual de Direito do Consumidor. São Paulo: Saraiva, 2003.

ALVES, Fabrício Germano. Proteção Constitucional do consumidor no âmbito da regulação publicitária. Natal: Espaço Internacional do Livro, 2013.

Atividade Legislativa do Projeto de Lei do Senado n ${ }^{\circ} 281$, de 2012 - Agenda Brasil 2015. Disponível em: $<$ https://www25.senado.leg.br/web/atividade/materias/-/materia/106768> Acesso em: 07 jul. 2016.

BENJAMIN, Antonio Herman V, et al. Manual de Direito do Consumidor. 6. ed. São Paulo: Revista dos Tribunais, 2014. 
BULOS, Uadi Lammêgo. Curso de Direito Constitucional. 6. ed. São Paulo: Saraiva, 2011.

BLUM, Rita Peixoto Ferreira. Direito do Consumidor na Internet. São Paulo: Quartier, 2002

BRASIL. Constituição (1988). Constituição da República Federativa do Brasil. promulgada em 5 de outubro de 1988.

Lei Federal $\mathbf{n}^{\text {o }}$ 8.078, de 11 de setembro de 1990. Dispõe sobre a proteção do consumidor e dá outras providências.

. Tribunal de Justiça do Distrito Federal. TJ-DF - ACJ: 20151010013067 , Relator: Oriana Piske, Data de Julgamento: 06/10/2015, 2a Turma Recursal dos Juizados Especiais do Distrito Federal, Data de Publicação: Publicado no DJE: 08/10/2015.

. Brasil está 'mergulhado' em recessão profunda, diz FMI. Disponível em < http://g1.globo.com/economia/noticia/2016/04/brasil-esta-mergulhado-em-recessao-economica-profunda-diz-fmi.html $>$ Acesso em: 14 jul. 2016.

COELHO, Fábio Ulhoa. Curso de Direito Comercial: direito de empresa. 13. ed. São Paulo: Saraiva, 2012, v. 3.

Comércio eletrônico deve crescer $18 \%$ e faturar $\mathbf{R} \$ \mathbf{5 6 , 8}$ bi em 2016. Disponível em < http://g1.globo.com/economia/noticia/2016/01/comercio-eletronico-deve-crescer-18-e-faturar-r-568-bi-em-2016.html > Acesso em: 14 jul. $/ 2016$.

. Decreto $n^{\circ} 7.962$, de 2013 de setembro de 2006. Regulamenta a Lei no 10.962, de 11 de outubro de 2004, e a Lei no 8.078, de 11 de setembro de 1990. Diário Oficial da União, Brasília, DF, 21 set. 2006.

. Tribunal de Justiça do Distrito Federal. TJ-DF -APC: 20140111789662,

Relator: Hector Valverde Santanna, Data de Julgamento: 09/09/2015. 6a Turma Cível, Data de Publicação: Publicado no DJE : 28/07/2015.

. Tribunal de Justiça do Mato Grosso. TJMT - AC 24.068 - CLASSE II - 23 - POCONÉ - $3^{\mathrm{a}}$ C.CÍV. Rel. Des. José Ferreira Leite - J. 28.06.2000

. Tribunal de Justiça de São Paulo. TJ-SP APL: 00030004220088260288 SP 0003000-42.2008.8.26.0288, Relator: Ferraz Felisardo, Data de Julgamento: 15/05/2013, 29a Câmara de Direito Privado, Data de Publicação: 15/05/2013. 
. Tribunal de Justiça de São Paulo. TJ-SP-APL: 00027329320128260434 SP 0002732-93.2012.8.26.0434, Relator: Soares Levada, Data de Julgamento: 30/03/2015, $34^{\mathrm{a}}$ Câmara de Direito Privado, Data de Publicação: 31/03/2015. EBIHARA, Igor Luiz. O regulamento autônomo e o seu papel na organização da Administração Pública Federal. Revista de Informação Legislativa. Ano 51 Número 202 abr.jun. 2014. Disponível em: <https://www2.senado.leg. br/bdsf/bitstream/handle/id/503046/001011328.pdf?sequence=1> Acesso em: 11 jul. 2016.

GOMIDE, Alexandre Junqueira. Direito de Arrependimento nos Contratos de Consumo. 1. ed. São Paulo: Almeida, 2014.

GONÇALVES, Carlos Roberto. Direito Civil Brasileiro: contratos e atos unilaterais. 8. ed. São Paulo: Saraiva, 2011, v. 3.

GRINOVER, Ada Pellegrini, et al. Código brasileiro de defesa do consumidor: comentado pelos autores ao anteprojeto. 8. ed. Rio de Janeiro: Forense Universitária, 2004.

MARQUES, Cláudia Lima. Contratos no Código de Defesa do Consumidor: o novo regime das relações contratuais. 4. ed. São Paulo: Revista dos Tribunais, 2002.

MARTINS, Plínio Lacerda. O abuso nas relações de consumo e o princípio da boa-fé. Rio de janeiro: Forense, 2002.

MATTOS, Analice Castor. Aspectos Relevantes dos Contratos de Consumo Eletrônico. Curitiba: Juruá, 2009.

NUNES, Luiz Antonio Rizzato. Curso de Direito do Consumidor. 7. ed. São Paulo: Saraiva, 2012.

SANSEVERINO, Paulo de Tarso Vieira. Responsabilidade Civil no Código do Consumidor e a Defesa do Fornecedor. 3. ed. São Paulo: Saraiva, 2010.

TARTUCE, Flávio, Daniel Amorim. Manual de Direito do Consumidor. 3. ed. São Paulo: Método. 2014. 
Sobre os Autores:

\section{Fabrício Germano Alves}

Advogado, Doutorado em Direito pela Universidade Federal do Rio Grande do Norte. Professor de Direito das Relações de Consumo, Direito Civil, Hermenêutica Jurídica e Teoria da Argumentação.

E-mail: fabriciogermano@hotmail.co.uk

\section{Halissa Reis}

Advogada, Tecnóloga em Gestão Pública pela Universidade Federal do Rio Grande do Norte. Especialista em Direito Civil e Processo Civil pela Universidade Federal do Rio Grande do Norte. E-mail: halissa_reis@hotmail.com

Submetido em: 05-12-2016

Aceito em: 24-05-2017 